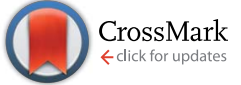

Cite this: J. Mater. Chem. A, 2015, 3, 23799

Received 11th August 2015

Accepted 20th October 2015

DOI: $10.1039 / c 5 t a 06309 d$

www.rsc.org/MaterialsA

\section{Bimetallic porous porphyrin polymer-derived non- precious metal electrocatalysts for oxygen reduction reactions $\dagger$}

\author{
Sebastian Brüller, ${ }^{a}$ Hai-Wei Liang, ${ }^{a}$ Ulrike I. Kramm, ${ }^{c}$ Joseph W. Krumpfer, ${ }^{a}$ \\ Xinliang Feng ${ }^{\star b}$ and Klaus Müllen*a
}

\begin{abstract}
The development of efficient and stable electrocatalysts on the basis of non-precious metals (Co, $\mathrm{Fe})$ is considered as one of the most promising routes to replace expensive and susceptible platinum as the oxygen reduction reaction (ORR) catalyst. Here we report a synthetic strategy for the precursor controlled, template-free preparation of novel mono- (Fe; $\mathrm{Co}$ ) and bimetallic (Fe/Co) nitrogen-doped porous carbons and their electrocatalytic performance towards the ORR. The precursors are composed of metal-porphyrin based conjugated microporous polymers (M-CMPs with $\mathrm{M}=\mathrm{Fe}$; $\mathrm{Co}$; Fe/Co) derived from polymerization of metalloporphyrins by the Suzuki polycondensation reaction, which enables the synthesis of bimetallic polymers with alternating metal-porphyrin units for the preparation of carbonbased catalysts with homogenously distributed $\mathrm{CoN}_{4}$ and $\mathrm{FeN}_{4}$ centres. Subsequent pyrolysis of the networks reveals the key role of pre-morphology and network composition on the active sites. ${ }^{57} \mathrm{Fe}-$ Mössbauer spectroscopy was conducted on iron catalysts ( $\mathrm{Fe}$; $\mathrm{Fe} / \mathrm{Co}$ ) to determine the coordination of Fe within the $\mathrm{N}$-doped carbon matrix and the catalytic activity-enhancing shift in electron density. In acidic media the bimetallic catalyst demonstrates a synergetic effect for cobalt and iron active sites, mainly through a 4-electron transfer process, achieving an onset potential of $0.88 \mathrm{~V}$ (versus a reversible hydrogen electrode) and a half-wave potential of $0.78 \mathrm{~V}$, which is only $0.06 \mathrm{~V}$ less than that of the stateof-the-art Pt/C catalyst.
\end{abstract}

\section{Introduction}

Electrochemical energy storage and conversion is of increasing importance to meet the progressive demand for energy, urging the development of new materials applied in many technologies such as batteries, electrolysers and fuel cells. For polyelectrolyte membrane fuel cells (PEMFCs), the common catalyst for the oxygen reduction reaction (ORR) is based on $\mathrm{Pt}$ or Pt-alloys that suffer from high costs, scarcity and the lack of stability., Versatile classes of materials, including molecular non-noble metal complexes, metal oxides, metal chalcogenides and metalfree heteroatom-doped carbons, have been evaluated as alternatives for Pt-based catalysts over the past several decades. ${ }^{3-13}$ In particular, nitrogen-coordinated transition metals have

\footnotetext{
${ }^{a}$ Max Planck Institute for Polymer Research, Ackermannweg 10, 55128 Mainz, Germany.E-mail: muellen@mpip-Mainz.mpg.de

${ }^{b}$ Department of Chemistry and Food Chemistry, Center for Advancing Electronics Dresden (cfaed), Technical University of Dresden, Mommsenstrasse 4, 01062 Dresden, Germany. E-mail: xinliang.feng@tu-Dresden.de

'Technical University of Darmstadt, Department of Materials- and Earth Science and Department of Chemistry, Chair of Catalysts and Electrocatalysts, JovankaBontschits-Str. 2, 64287 Darmstadt, Germany

$\dagger$ Electronic supplementary information (ESI) available. See DOI: 10.1039/c5ta06309d
}

received attention since Jasinski reported the electrocatalytic activity of Co-phthalocyanine in $1964 .{ }^{\mathbf{1 4}}$ However, molecular catalysts exhibit neither sufficient catalytic activity nor longterm stability due to decomplexation of the transition metal. ${ }^{\mathbf{1 5}}$ To overcome this drawback, porous carbon supports have been impregnated with nitrogen-containing transition metal complexes and subsequently converted into metal-nitrogendoped carbon upon pyrolysis under an inert atmosphere. ${ }^{\mathbf{1 6 - 2 1}}$ Thus, the activity and durability of the catalyst during the ORR process can be significantly improved. ${ }^{22}$

Although the detailed structure of the catalytically active sites remains elusive, it is commonly accepted that nitrogencomplexed transition metals $\left(\mathrm{MN}_{4-x}, \mathrm{M}\right.$ : Fe, Co, Cr, Mn) incorporated within a carbon matrix play a crucial role in the ORR, particularly in acidic media. ${ }^{7,23}$ In addition to nitrogencontaining metal complexes such as phthalocyanines and porphyrins, which are composed of $\mathrm{MN}_{4}$ centers, much effort has been devoted to the development of highly active ORR catalysts by simply blending individual carbon, nitrogen and metal sources or metal-chelating polymers. ${ }^{21,23-25}$ Although $\mathbf{M N}_{4}$ sites can be created by thermal treatment of such precursor systems, numerous metallic nanoparticles of different sizes are often formed during pyrolysis. ${ }^{\mathbf{2 6 - 2 8}}$ This undesired agglomeration of metals is commonly observed for the impregnation 
method, in which the metal complex precursor is weakly bound or physically adsorbed on the carbon support, leading to a decrease in the catalytic activity of these materials. ${ }^{29,30}$ For this reason, the optimization of the precursor composition has been intensively studied, and it has been found that a suitable amount of metal within the precursor or sulfur as an additive is capable to limit metal nanoparticle growth. ${ }^{18,31-34}$ Additionally, to provide a high density of active sites as well as unhindered mass transport, the carbon support must feature a large surface area and porous structure. Therefore, hard templates, such as ordered porous silicas or metal oxides, have also been used as supports for ORR catalysts. ${ }^{21,35,36}$ However, the removal of the costly inorganic template is difficult and increases the number of working steps.

To circumvent such disadvantages, metal-organic frameworks (MOFs) have been recently reported to act as formative soft templates, which can be decomposed during pyrolysis. ${ }^{37}$ Nevertheless, this fabrication method requires an elaborate heat treatment in a hazardous ammonia atmosphere and is associated with enormous mass loss. In the end, precursorcontrolled pyrolysis of porous polymer frameworks has realized the template-free preparation of self-supporting metalnitrogen-doped carbon materials in a one-step approach. ${ }^{38}$ Polymer frameworks consisting of conjugated immobilized metal-porphyrins offer an attractive route for the formation of large surface areas with intrinsic micropores and a maximum density of the desired $\mathrm{MN}_{4}$ units. The fixation of the $\mathrm{MN}_{4}$-sites within the rigid polymer framework and its high thermal stability further alleviate the formation of metal nanoparticle agglomerates during the pyrolysis process. With respect to this finding, we recently reported the preparation of self-supported cobalt-containing nitrogen-doped carbons as ORR catalysts through pyrolysis of a porous conjugated cobalt porphyrin polymer synthesized by Yamamoto polycondensation, revealing promising electrocatalytic performance in acidic media. ${ }^{39}$ Numerous comparative and computational studies have indicated that iron-containing and particularly bimetallic catalysts have enhanced activity towards the ORR..$^{40-42}$ Consequently, we herein demonstrate a precursor-controlled pyrolysis of iron, cobalt and bimetallic porphyrin-based conjugated microporous polymers that were synthesized by Suzuki polycondensation. This synthetic approach gives easy access to a homogenous distribution of $\mathrm{Fe}$ - and/or Co-complexes within a conjugated carbon network which represents a major advantage over typical methods that provide arbitrary coverage onto supports. Furthermore, the $\mathrm{Fe}$ - and Co-sites are arranged in an alternating sequence throughout the entire precursor increasing the chance to promote synergetic effects of associated active sites. Another significant feature of this synthetic strategy is the ability to tune the pore characteristics through manipulating the size and connectivity of the monomers, which can lead to an efficient mass transport. Finally, the rigidity and high thermal stability of the porphyrin network confine the formation of metal nanoparticles during the pyrolysis process, providing the retention of catalytically active $\mathrm{MN}_{4}$-sites. ${ }^{57} \mathrm{Fe}$-Mössbauer spectroscopy indicates a shift of electron density from neighboring $\mathrm{CoN}_{4}$-sites to $\mathrm{FeN}_{4}$-sites. This synergetic effect of bimetallic $(\mathrm{Fe} / \mathrm{Co})$ nitrogen-doped carbons is reflected by the higher ORR onset potential $(0.88 \mathrm{~V})$ in acidic media compared with the catalysts derived from monometallic porphyrin networks.

\section{Experimental}

\subsection{Synthesis of (metal-)porphyrin derivatives}

The porphyrin monomers, 5,10,15,20-tetrakis(4'-bromophenyl)porphyrin, 5,10,15,20-tetrakis( $4^{\prime}$-benzenediboronic acid bis(pinacol) ester) porphyrin, iron(III) 5,10,15,20-tetrakis(4'-bromophenyl)porphyrin chloride, cobalt(II) 5,10,15,20-tetrakis( $4^{\prime}$-bromophenyl)porphyrin and cobalt(II) 5,10,15,20-tetrakis( $4^{\prime}$-benzenediboronic acid bis(pinacol) ester) porphine, were synthesized according to the literature or with slight modifications..$^{43}$ All details regarding the synthesis and the characterization of the compounds are presented in the ESI. $\dagger$

\subsection{Synthesis of CMP}

From Suzuki cross-coupling polycondensation following the procedure from the literature, metal-free, monometallic and bimetallic CMPs were obtained. ${ }^{44}$ Metal-free CMP: 5,10,15,20tetrakis $\left(4^{\prime}\right.$-bromophenyl)porphyrin $\left([p-\mathrm{Br}]_{4} \mathrm{TPP}\right)$ and $5,10,15,20$ tetrakis(4'-benzenediboronic acid bis(pinacol) ester) porphyrin ([p-BOR $\left.]_{4} \mathrm{TPP}\right)$; monometallic Fe-CMP and Co-CMP: $\left([p \text {-Br }]_{4^{-}}\right.$ FeTPP) or ([p-Br $]_{4}$ CoTPP) and 1,4-benzenediboronic acid bis(pinacol) ester; bimetallic Fe/Co-CMP: ([p-Br $\left.]_{4} \mathrm{FeTPP}\right)$ and ([p$\left.\mathrm{BOR}]_{4} \mathrm{CoTPP}\right)$. The schematic polymer structures and their properties are displayed in Fig. 1 and S1.†

\subsection{Preparation of pyrolyzed CMP}

For the carbonization step, 200-300 $\mathrm{mg}$ of the CMP were placed into a quartz boat, which was introduced into a ceramic oven, and pyrolyzed at various temperatures of 700,800 and $900{ }^{\circ} \mathrm{C}$ under flowing nitrogen $(300 \mathrm{sccm})$. First, the temperature was set to $200^{\circ} \mathrm{C}$ for $2 \mathrm{~h}$ to remove solvents and adsorbed water from the CMP. With a heating rate of $5 \mathrm{~K} \mathrm{~min}^{-1}$ the oven reached the specific temperature and held for an additional $2 \mathrm{~h}$ before being cooled down by natural convection. These samples are denoted as M-CMP-700*, M-CMP-800* and M-CMP-900*. After etching with semi-concentrated hydrochloric acid $(6.0 \mathrm{M})$ for $16 \mathrm{~h}$, the materials were subjected to a second pyrolysis in an inert atmosphere under the same conditions as the first pyrolysis treatment. The metal-nitrogen-doped porous carbons are named M-CMP-700, M-CMP-800 and M-CMP-900 (M: Fe/Co; Co; Fe), respectively. The final catalyst was used as obtained.

\subsection{Physicochemical characterization}

Field-desorption mass spectra were measured on a VG Instrument ZAB 2-SE-FPD. Matrix-assisted laser desorption ionization time-of-flight (MALDI-TOF) experiments were conducted on a Bruker Reflex II TOF spectrometer equipped with a $337 \mathrm{~nm}$ nitrogen laser. Samples were analyzed from the solid state mixed within a matrix of tetracyanoquinodimethane (TCNQ). Solution UV-Vis spectra were recorded on a Perkin-Elmer Lambda 900 spectrophotometer. The spectra were corrected by 
a) Fe/Co-CMP

.
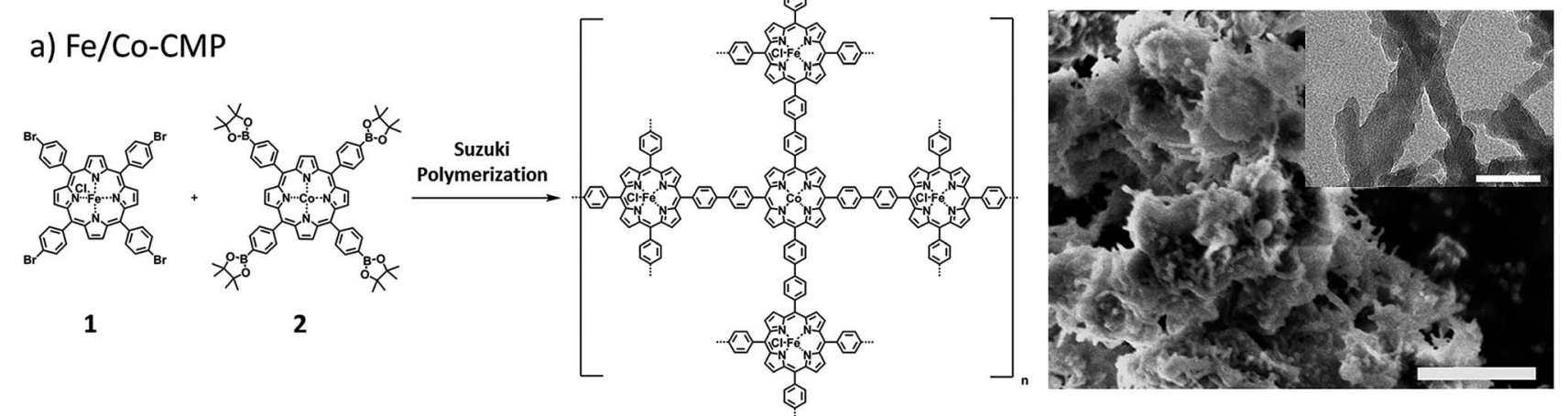

b) Co-CMP

c) Fe-CMP
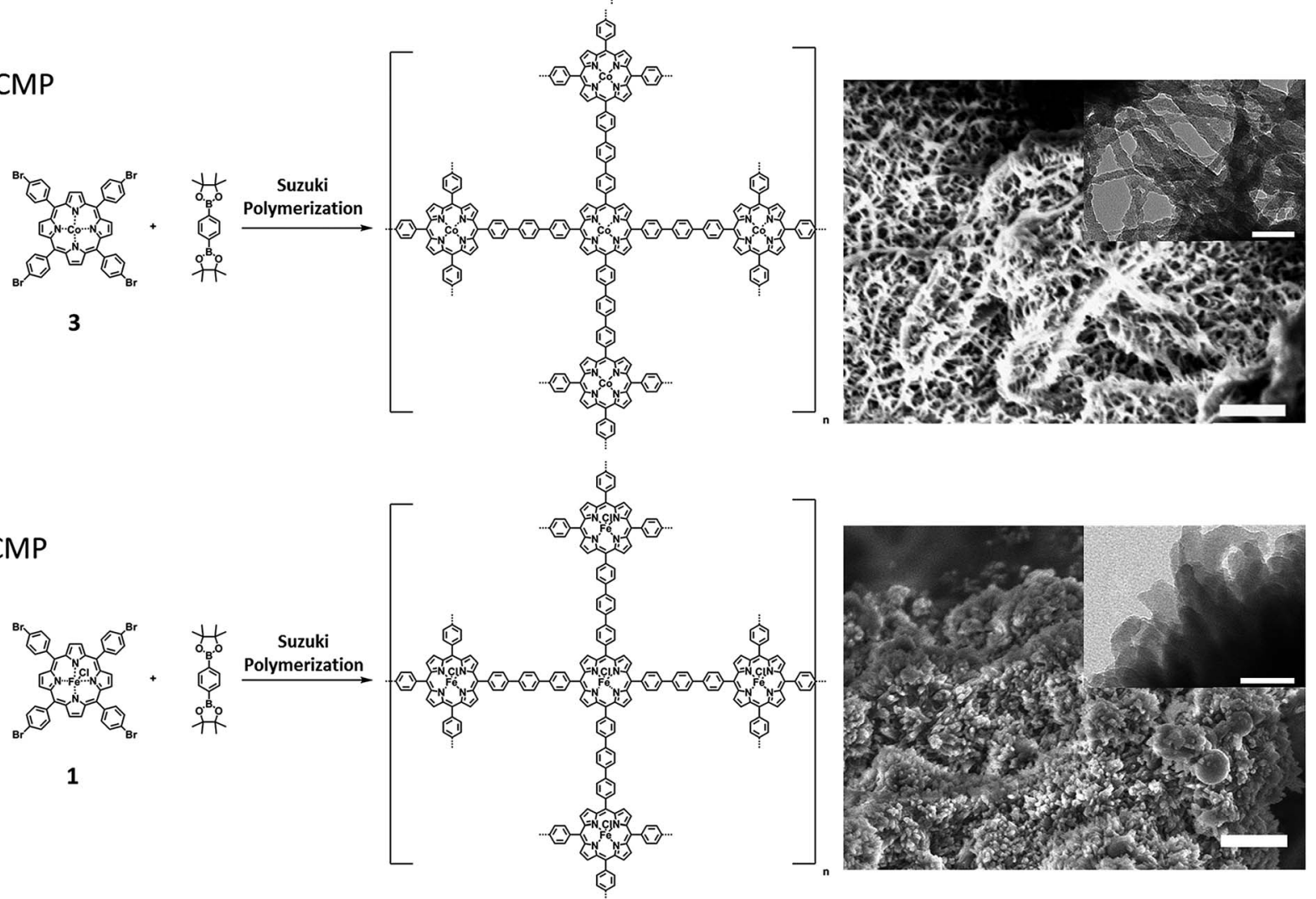

Fig. 1 Schematic representation of the synthesis and structure of (a) Fe/Co-CMP, (b) Co-CMP and (c) Fe-CMP and their nanosized morphology imaged by SEM (scale bars $1 \mu \mathrm{m}$ ) and TEM (scale bars $0.1 \mu \mathrm{m}$ ).

subtracting the background, which was measured with a cuvette filled with pure solvent. ${ }^{1} \mathrm{H}$-NMR and ${ }^{13} \mathrm{C}$-NMR experiments on soluble compounds were performed on the listed deuterated solvents (as internal standards) on a Bruker AMX 300, Bruker DRX 500 or Bruker DRX 700 spectrometer. Solid-state ${ }^{13} \mathrm{C}\left[{ }^{1} \mathrm{H}\right]$ cross polarization (CP) NMR measurements were recorded on a Bruker ASX 500 spectrometer at $75 \mathrm{MHz}$ and a magic angle spinning (MAS) frequency of $10 \mathrm{kHz}$. Fourier transform infrared (FTIR) spectra were measured with a Nicolet 730 spectrometer equipped with an attenuated reflection (ATR) module. Thermogravimetric analysis was performed on a Toledo TGA/SDTA 851e (Mettler) with a heating rate of $5 \mathrm{~K} \mathrm{~min}^{-1}$ in a nitrogen atmosphere. Nitrogen sorption measurements were conducted at $77 \mathrm{~K}$ on a TriStar 3020 volumetric analyzer (Micromeritics). All samples were degassed at $200{ }^{\circ} \mathrm{C}$ for at least $4 \mathrm{~h}$ prior to every measurement. Specific surface areas were determined by the standard Brunauer-Emmett-Teller (BET) method based on the relative pressure between 0.05 and 0.20 . The pore size distribution (PSD) was calculated by the Barrett-Joyner-Halenda (BJH) method. Scanning electron microscopy (SEM) was performed on a field emission micro-analyzer (Gemini LEO 1530). Transmission electron microscopy (TEM) was carried out on a JEM-1400 (JEOL Ltd.). The sample was dispersed in ethanol by ultra-sonication and dropped onto a carbon-coated copper grid. High resolution TEM (HRTEM) and energy dispersive X-ray (EDX) measurements were conducted on a Tecnai F20 (FEI) with a beam voltage of $200 \mathrm{kV}$. X-ray photoelectron spectroscopy (XPS) was carried out on an AXIS Ultra DLD system from Kratos with an $\mathrm{Al} \mathrm{K} \alpha$ radiation source. Mössbauer measurements were conducted at room temperature with a CMCA-550 (Wissel) 
equipped with a constant electronic drive system with a triangular reference waveform (Halder Electronics). The radiation source ${ }^{57} \mathrm{Co} / \mathrm{Rh}$ was used, and the calibration of the velocity scale and the isomer shift was made with respect to $\alpha$-iron.

\subsection{Electrochemical measurements}

All electrochemical measurements were performed in a standard three-compartment cell using a WaveDriver 20 bipotentiostat (Pine Instrument Company, USA) at room temperature. The counter electrode and reference electrode were a platinum wire and an $\mathrm{Ag} / \mathrm{AgCl}(4 \mathrm{M} \mathrm{KCl})$ electrode, respectively. Since all potentials in this work refer to that of the reversible hydrogen electrode (RHE), a potential difference of $0.23 \mathrm{~V}$ - arising from the potential difference of the RHE vs. Ag/ $\mathrm{AgCl}$ - is taken into account. The working electrodes, a rotating disc electrode (RDE) composed of a glassy carbon disc $(5.0 \mathrm{~mm}$ diameter) and a rotating ring disc electrode (RRDE) constructed of a glassy carbon disc (5.61 $\mathrm{mm}$ diameter) surrounded by an outer Pt-ring (6.25 mm inner-diameter and $7.92 \mathrm{~mm}$ outerdiameter), served as substrates for the catalyst ink. The catalyst ink was prepared by suspending $10 \mathrm{mg}$ catalyst with $100 \mu \mathrm{L}$ Nafion solution (5 wt\%) and $400 \mu \mathrm{L}$ ethanol in an ultrasonic bath. A loading of $120 \mu \mathrm{g}$ catalyst $(6 \mu \mathrm{L})$ was pipetted onto the glassy carbon surface of the RDE/RRDE and left to dry in air at room temperature. Before a voltammogram was recorded a reduction/oxidation cycle was performed to remove static current and weakly bound electro-active compounds. The linear sweep voltammograms (LSVs) were measured in the cathodic direction using $\mathrm{O}_{2}$-saturated $0.5 \mathrm{M} \mathrm{H}_{2} \mathrm{SO}_{4}$ as the electrolyte. The rotation speed was $1600 \mathrm{rpm}$, and the sweep rate was $5 \mathrm{mV} \mathrm{s}^{-1}$. Since the double layer capacitance contributes to the polarization, oxygen was removed from the electrolyte by bubbling with argon for $30 \mathrm{~min}$, and then a voltammogram in the $\mathrm{O}_{2}$-free electrolyte was evaluated. The oxygen reduction current was determined from the difference of the voltammograms measured in $\mathrm{O}_{2}$-saturated and $\mathrm{O}_{2}$-free electrolytes. To determine the peroxide generated by the ORR-catalysts, a potential of $1.4 \mathrm{~V} v s$. RHE was set on the Pt-ring electrode of the RRDE.

\section{Results and discussion}

\subsection{Characterization of CMP}

The porphyrin polymer networks were synthesized via Suzuki cross-coupling polycondensation in the presence of a catalytic amount of tetrakis(triphenylphosphine)palladium(0). Polymerization of monomers $\mathbf{1}$ and $\mathbf{2}$ produced bimetallic porphyrin polymer (Fe/Co-CMP) (Fig. 1). The monometallic Co-CMP and Fe-CMP were also prepared under the same reaction conditions from 1,4-benzenediboronic acid bis(pinacol) ester with monomers 3 and 1, respectively (for details see the Experimental section). The mono- and bimetallic CMPs were analyzed by FTIR spectroscopy. The characteristic $\mathrm{N}-\mathrm{Fe}$ and $\mathrm{N}-\mathrm{Co}$ vibration bands at $997 \mathrm{~cm}^{-1}$ and $1001 \mathrm{~cm}^{-1}$, respectively, remained after the polymerization (Fig. S1a-h $\dagger$ ) indicating the stability of the metal-nitrogen complex under these reaction conditions. The aryl-aryl-bond formation is further indicated by the significantly diminished intensities of the $\mathrm{C}-\mathrm{Br}$ and $\mathrm{B}-\mathrm{O}$ stretching bands at $1072 \mathrm{~cm}^{-1}$ and $1348 \mathrm{~cm}^{-1}$, respectively. To gain further insight into the polymerization reaction, solid state ${ }^{13} \mathrm{C}-\mathrm{NMR}$ spectroscopy was performed on a metal-free CMP, which was obtained from the polymerization of metal-free porphyrins $5,10,15,20$-tetrakis ( $4^{\prime}$-bromophenyl)porphine and 5,10,15,20-tetrakis( $4^{\prime}$-benzenediboronic acid bis(pinacol) ester) porphine (Fig. S1i and $\mathrm{j} \dagger$ ). With increasing reaction time, the MAS ${ }^{13}$ C-NMR-spectra of the metal-free CMP displayed decreasing signal intensity for the peaks corresponding to the carbons $\mathrm{C}_{\mathrm{Ar}}-\mathrm{Br}(119 \mathrm{ppm})$ and $\mathrm{C}_{\mathrm{Ar}}-\mathrm{B}$ (121 ppm). Simultaneously, an increase in the peak at $\sim 140 \mathrm{ppm}$ - characteristic of aromatic quaternary carbons - was observed..$^{45}$ These results indicate successful formation of CMPs with high polymerization degree.

From nitrogen adsorption measurements, the surface area was calculated by the Brunauer-Emmett-Teller method (BET) to be as high as $463,597,488$, and $352 \mathrm{~m}^{2} \mathrm{~g}^{-1}$ for Fe/Co-CMP, Co-CMP, Fe-CMP, and metal-free CMP, respectively. These CMPs were categorized as type I isotherms, indicating that the surface area mainly consists of micropores. The absence of any hysteresis in the isotherms at low pressure indicated porenetwork effects (e.g., swelling) - a characteristic property of polymers with intrinsic microporosity. ${ }^{46}$ In the case of $\mathrm{Fe} / \mathrm{Co}-$ CMP and Co-CMP, pores larger than $10 \mathrm{~nm}$ also contributed to the surface area (Fig. S1k-n $\dagger$ ). The pyrolysis behavior of the metal-porphyrin networks was initially examined by thermal gravimetric analysis (TGA), which demonstrated a significantly elevated decomposition temperature of the rigid metalporphyrin networks than that of the molecular porphyrins (Fig. S2 $\dagger$ ). Furthermore, TGA showed that Fe-CMP began to decompose at lower temperatures than the Co-containing networks, Co-CMP and Co/Fe-CMP, both of which exhibiting equal thermal stability and a weight loss of $26 \%$ up to $800{ }^{\circ} \mathrm{C}$. This is likely due to the lower stability of the iron complex and the formation of iron nanoparticles, which further catalyze the decomposition of the carbon matrix (see below).

\subsection{Characterization of pyrolysed CMP}

The morphology and nanoparticle formation in the networks after pyrolysis are shown in Fig. 2. SEM analysis confirmed the retention of the microstructure in all samples after high temperature treatment, thereby demonstrating the unique thermal stability of the polymeric network. TEM analysis revealed that metal nanoparticles of 5-30 nm formed during pyrolysis are decorated on the carbon matrix. Nevertheless, the amount and diameter of the metal nanoparticles are much smaller than those of the previously reported materials based on hard and soft templates. ${ }^{\mathbf{4 7}, 48}$ High-resolution TEM investigation of Fe-CMP-800* indicated that $\mathrm{Fe}$ nanoparticles with diameters between 5 and $15 \mathrm{~nm}$ were composed of iron carbide cores encapsulated by an "onion-like" carbon shell (Fig. S3 $\dagger$ ). The amount and size of metal nanoparticles of Fe-CMP-800* were larger than those of the cobalt containing materials, which can be explained by the lower thermal stability of Fe-CMP. Furthermore, the migration of Fe nanoparticles was facilitated 


\section{Pyrolysis}
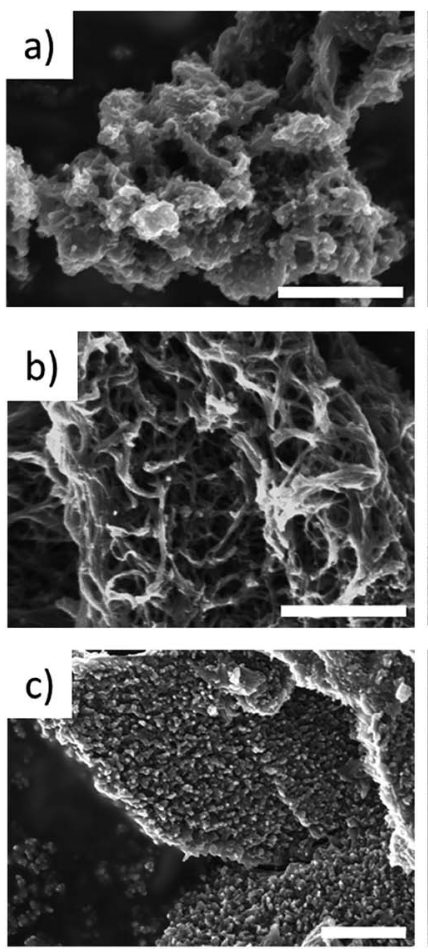
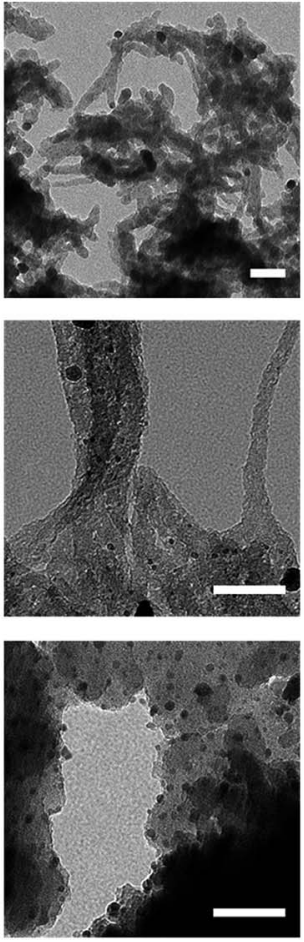

\section{Acid Leaching and 2. Pyrolysis}
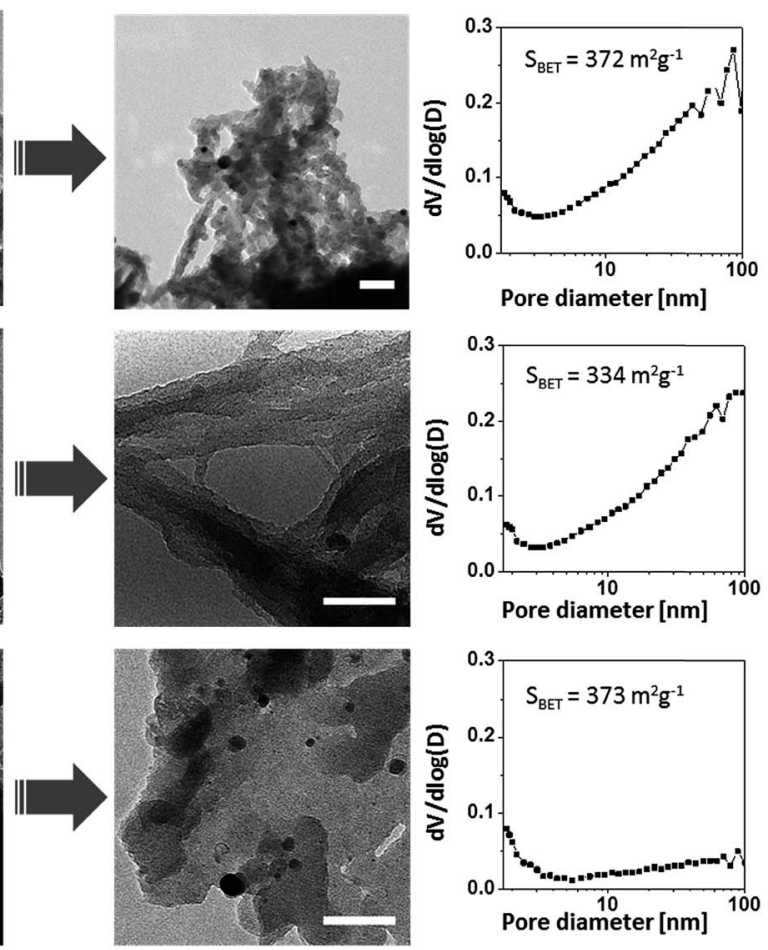

Fig. 2 SEM (scale bars, $1 \mu \mathrm{m}$ ) and TEM (scale bars, $0.1 \mu \mathrm{m}$ ) images before and after leaching and second pyrolysis and its corresponding BET surface area and pore size distribution of (a) Fe/Co-CMP-800, (b) Co-CMP-800 and (c) Fe-CMP-800.

by the microporous, monolithic morphology of Fe-CMP-800* (Fig. 2). By contrast, the morphology of Co-CMP-800* revealed a discontinuous network with a ribbon-like structure composed of fibers with diameters of 20 to $50 \mathrm{~nm}$, which limits the migration of Co nanoparticles. From HRTEM combined with EDX, a uniform distribution of atomic cobalt and iron within a nitrogen-doped carbon matrix could be observed in $\mathrm{Fe} / \mathrm{Co}-$ CMP-800* (Fig. S4 and S5†). Based on these observations, we assume that the nucleation and diffusion of metal nanoparticles within the carbon matrix is substantially suppressed by two factors: (1) the higher thermal stability of the $\mathrm{CoN}_{4}$ complex compared with the $\mathrm{FeN}_{4}$-complex; (2) the microstructure composed of interconnected nanorods found in the cobaltcontaining CMPs. Another type of nanoparticle with diameters up to $30 \mathrm{~nm}$ was identified by EDX as crystalline palladium, the presence of which is attributed to the confinement of the Pd-catalyst within the polymer networks during Suzuki polymerization. These Pd nanoparticles did not reveal any significant contribution to the ORR as confirmed by the ORR data of the pyrolyzed Fe- and Co-free CMPs (see below).

To expose more active sites, the metal-nanoparticles were leached out of the M-CMP-800* samples and the networks were subsequently subjected to a second heat treatment at $800{ }^{\circ} \mathrm{C} .{ }^{42}$ These samples are denoted as Fe/Co-CMP-800, Co-CMP-800 and Fe-CMP-800, respectively. Interestingly, the surface area of $\mathrm{Fe} /$ Co-CMP-800 $\left(372 \mathrm{~m}^{2} \mathrm{~g}^{-1}\right)$, Co-CMP-800 $\left(334 \mathrm{~m}^{2} \mathrm{~g}^{-1}\right)$ and FeCMP-800 $\left(373 \mathrm{~m}^{2} \mathrm{~g}^{-1}\right)$ independently reached similar values from the initial surface area and morphology. XPS was used to determine the chemical composition of the pyrolyzed networks. Analysis of M-CMP-800 displayed peaks for C1s, N1s, Fe 2p and/or Co 2p in all M-CMP-800 (Fig. 3 and S6†). Additional peaks assigned to boron and oxygen arose from the decomposition products of unreacted boronic acid groups and $\mathrm{O}_{2}$ or $\mathrm{H}_{2} \mathrm{O}$ adsorbed from air. The overall nitrogen content of the monometallic catalysts Co-CMP-800 and Fe-CMP-800 (2.5\% N) was lower than that of Fe/Co-CMP-800 $(3.7 \% \mathrm{~N})$. Nevertheless, considering the initial content of nitrogen in the polymers (approximately $5.76 \% \mathrm{~N}$ ), a much larger relative fraction of nitrogen remained intact compared with other preparation approaches. ${ }^{48}$ This might be due to the higher intrinsic thermal stability of the M-CMP network. The chemical nature of porphyrinic nitrogen can be transformed into several different species upon pyrolysis, such as graphitic, pyrrolic or pyridinic nitrogen. To analyze the different nitrogen-containing carbon species of the samples, the high-resolution N1s spectra were deconvoluted into their individual signals. Retention of $0.6 \%$ metal-coordinated nitrogen (398.7 eV) was revealed for Fe-CMP800 , whereas the ratio in the cobalt containing catalysts CoCMP-800 and Fe/Co-CMP-800 remained at a higher level of $1.0 \%$ and $1.2 \%$, respectively. The ratio of graphitic nitrogen is increasing from Co-CMP-800 over Fe-CMP-800 to Fe/Co-CMP800. Graphitic nitrogen can enhance the conductivity of the carbon matrix, which can decrease the overall resistance within the material. In all samples pyrrolic and pyridinic nitrogen were formed in minor proportions. Furthermore, the metal content of Fe-CMP-800 and Co-CMP-800 determined by XPS was $0.29 \%$ 

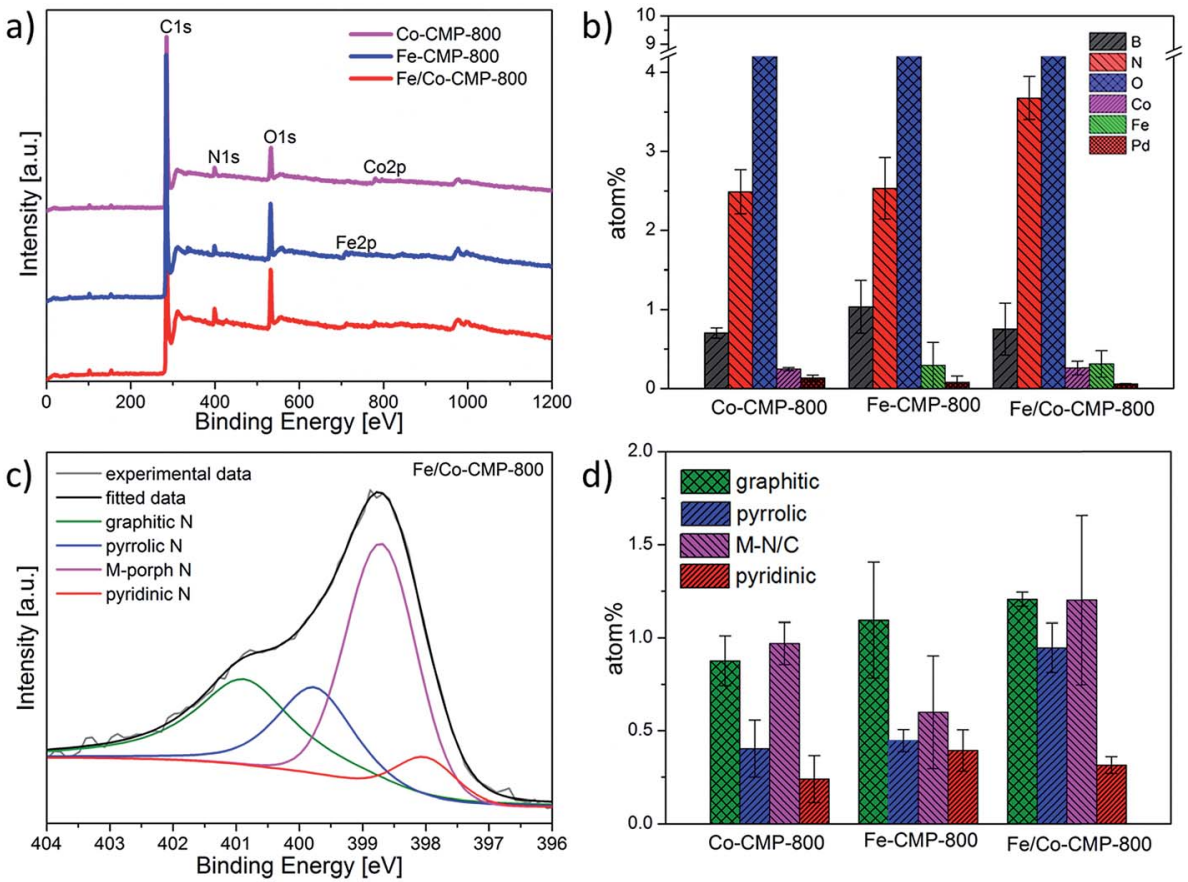

Fig. 3 (a) XPS spectra of M-CMP-800 recorded from 0 to $1100 \mathrm{eV}$. (b) Elemental composition of M-CMP-800 (excluding carbon). (c) Highresolution N1s XPS spectra of Fe/Co-CMP-800. (d) Content of specific nitrogen-bonding configurations in M-CMP-800.

Fe and $0.25 \%$ Co, respectively, that is 3 to 7 times higher than that for metal-nitrogen doped carbons obtained from the impregnation method. ${ }^{49} \mathrm{Fe} / \mathrm{Co}-\mathrm{CMP}-800$ revealed a total metal content of $0.57 \%(0.31 \% \mathrm{Fe}, 0.26 \% \mathrm{Co})$. Because most of the noncoordinated metal - with the exception of encapsulated nanoparticles - was etched out, the higher metal ratio in the bimetallic catalyst Fe/Co-CMP 800 suggests the presence of more active sites.

To evaluate the nature of the active sites, the iron-containing catalysts were subjected to ${ }^{57} \mathrm{Fe}-\mathrm{Mössbauer}$ spectroscopy studies. Structural transformations due to pyrolysis were already confirmed via high resolution nitrogen XPS. The Mössbauer spectra of both catalysts are given in Fig. 4 and reveal a heterogeneous composition of the catalysts with respect to iron. Both catalysts contain three $\mathrm{FeN}_{4}$-centers (D1-D3) and a minor amount of iron species without nitrogen coordination that correspond to iron nanoparticles and iron carbide. Mössbauer parameters and assignments for the iron species are summarized in Table 1 . The species assignments were made by a comparison of the Mössbauer parameters of our iron sites to values reported in the literature on $\mathrm{FeN}_{4}$-macrocycles and inorganic iron compounds. Major disparities between the deconvoluted spectra of both catalysts are related to the absorption areas of the different iron sites. Doublet D1 (green) corresponds to ferrous $\mathrm{FeN}_{4}$ in a low-spin state $(S=0)$ that was reported to be the active species towards the ORR in other porphyrin-based and alternatively prepared catalysts. ${ }^{26,28,50}$ The doublet D2 has Mössbauer parameters similar to those of crystalline iron phthalocyanine (FePc). ${ }^{51}$ In its crystalline form, both the square planar nitrogen coordination as well as interactions with nitrogen atoms in the axial direction (from FePc molecules on top or below) contribute to the quadrupole splitting, which is much larger than other $\mathrm{Fe}(\mathrm{II}) \mathrm{N}_{4}$ sites with intermediate spin. We assume that a similar pseudo-sixfold coordination of D2 is exclusively realized inside the material and inhibits its contribution to the catalytic activity. Doublet D3 can be assigned to the square planar $\mathrm{Fe}(\mathrm{II})-\mathrm{N}_{4}$ with intermediate spin. ${ }^{52}$ In the bimetallic catalyst Fe/Co-CMP-800 doublet D1 represents the major iron species whereas the monometallic catalyst Fe-CMP-800 primarily consists of the iron species assigned to D2. Such distinct formation of iron species is reasonable in consideration of the discontinuous and the contiguous morphology of Fe/Co-CMP-800 and Fe-CMP-800, respectively. Besides the morphology, the chemical structure of the precursor influences the formation and growth of iron nanoparticles which causes further destruction of active sites during heat treatment. ${ }^{29,34}$ Because of the lower solubility of carbon in cobalt than in iron at pyrolysis temperatures, the accumulation of nanoparticles is less pronounced for cobalt containing catalysts. ${ }^{5,54}$ These are important points in terms of possible optimization of the synthesis routes. Additionally, the $3 \mathrm{~d}$ electron density at the iron center of Fe/Co-CMP-800 is more favorable for ORR catalysis, as indicated by the higher isomer shift of D1 (0.46 versus $\left.0.42 \mathrm{~mm} \mathrm{~s}^{-1}\right){ }^{26}$ The slightly higher absorption area of D1 and especially its higher isomer shift of Fe/Co-CMP-800 towards Fe-CMP-800 can explain the higher catalytic activity. The charge transfer from neighboring cobalt sites might be the cause of this higher isomer shift, but a more detailed investigation would be required to confirm this.

\subsection{Electrochemical characterization}

To evaluate the ORR activity and selectivity, LSVs were recorded in $\mathrm{N}_{2}$ - and $\mathrm{O}_{2}$-saturated $0.5 \mathrm{M} \mathrm{H}_{2} \mathrm{SO}_{4}$ using a $\mathrm{RDE}$ with a catalyst 
a)
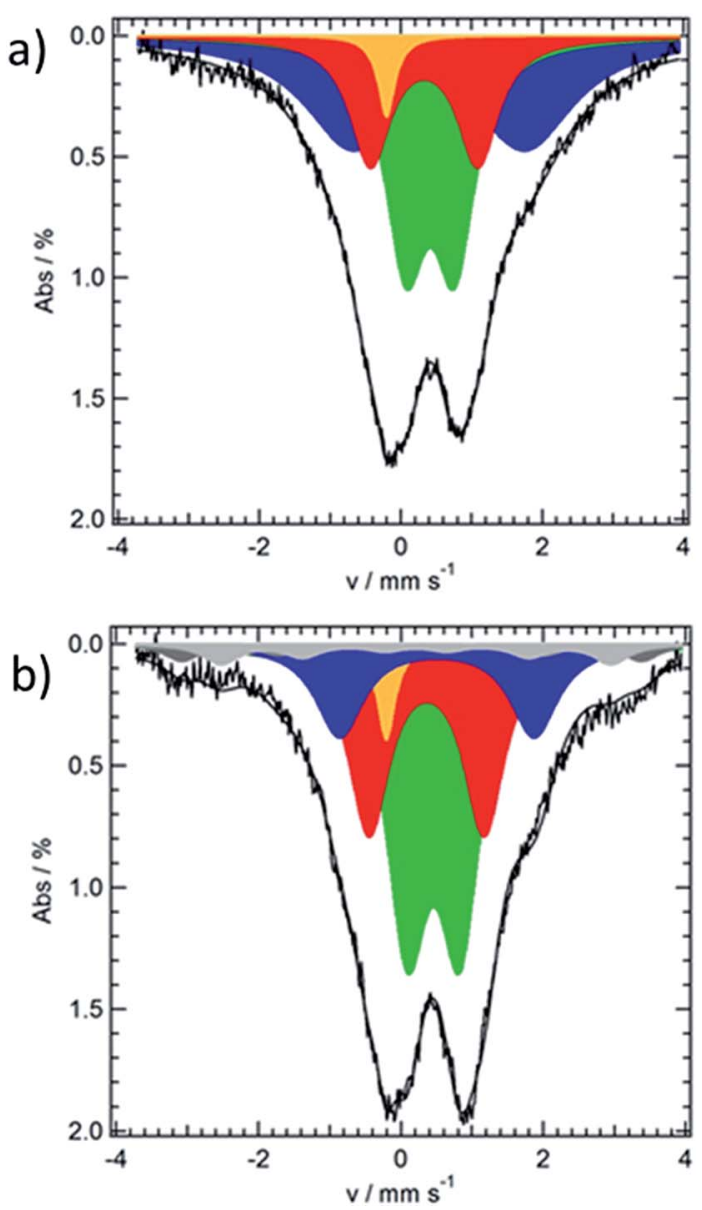

Fig. 4 Mössbauer spectra of (a) Fe-CMP-800 and (b) Fe/Co-CMP800 depicting ratio of assigned iron species.

loading of $0.6 \mathrm{mg} \mathrm{cm} \mathrm{c}^{-2}$. First, the influence of the pyrolysis temperature on the electrocatalytic activity of $\mathrm{Fe} / \mathrm{Co}-\mathrm{CMP}$ was investigated. As displayed in Fig. $5 \mathrm{a}, 800{ }^{\circ} \mathrm{C}$ was found to be the optimized pyrolysis temperature in accordance with temperature-activity trends in carbon-supported porphyrinbased catalysts. ${ }^{55}$ In Fig. 5b, the polarization curves of metalfree CMP-800, Co-CMP-800, Fe-CMP, Fe/Co-CMP-800 and Pt/C are depicted. The onset-potential of the non-precious metalbased catalysts increased in the following order: Co-CMP-800 (0.82 V), Fe-CMP-800 (0.85 V) and Fe/Co-CMP-800 (0.88 V). The metal-free catalyst CMP-800 showed poor activity, verifying the negligible contribution from the Pd-nanoparticles to the ORR. These results also suggest the crucial role of $\mathrm{FeN}_{4^{-}}$and $\mathrm{CoN}_{4^{-}}$ sites in nitrogen-doped carbons for the electrocatalytic reduction of oxygen in acidic media. In accordance with the intrinsic nature of the active sites, both iron-containing catalysts exhibit a similar onset potential. However, the sharp decline in the polarization curve of $\mathrm{Fe} / \mathrm{Co}-\mathrm{CMP}-800$ suggests the presence of more exposed active sites and/or a higher turnover frequency for the bimetallic catalyst. This behavior can be explained by the higher electron density at the iron sites, as indicated from the Mössbauer analysis. Furthermore, the half-wave potentials of Co-CMP-800 and Fe-CMP-800 were determined to be $0.74 \mathrm{~V}$ that is comparable to other monometallic porphyrin polymer-derived catalysts. ${ }^{38,39,56}$ Strikingly, the bimetallic catalyst Fe/Co-CMP-800 demonstrated a more positive half-wave potential of $0.76 \mathrm{~V}$, which is only $0.08 \mathrm{~V}$ less than that of $\mathrm{Pt} / \mathrm{C}(20 \mathrm{wt} \%$, BASF).

Aside from low overpotential, a selective reduction of oxygen to water is relevant for its application in PEMFCs. Incomplete $2 \mathrm{e}^{-}$-reduction releases hydrogen peroxide, which might corrode the cell membrane and the catalyst material itself. Furthermore, the power output would strongly benefit from the complete reduction of oxygen. Therefore, the electron transfer number (ETN) of the electrocatalysts and their corresponding $\mathrm{H}_{2} \mathrm{O}_{2}$ ratios were determined by RRDE measurements (Fig. 5c). From the data, the $\mathrm{H}_{2} \mathrm{O}_{2}$ evolution of Co-CMP-800 is significantly higher than that observed for the iron-containing catalysts FeCMP-800 and Fe/Co-CMP-800. This result indicates preferential $2 \mathrm{e}^{-}$-reduction in Co-CMP-800 with respect to Fe-containing catalysts and is in accordance with previous findings on selectivity in metal-nitrogen-doped catalysts. ${ }^{42}$ Interestingly, the

Table 1 Average Mössbauer parameters of the two catalysts and assignments for the iron species ${ }^{a}$

\begin{tabular}{|c|c|c|c|c|c|c|c|}
\hline & $\delta_{\text {iso }}$ & $\Delta E_{\mathrm{Q}} / \mathrm{mm} \mathrm{s}^{-1}$ & fwhm & $H_{\mathrm{o}} / \mathrm{T}$ & Fe-CMP-800 $\kappa^{2}=0.77 \mathrm{~A} / \%$ & $\mathrm{Fe} / \mathrm{Co}-\mathrm{CMP}-800 \kappa^{2}=1.01 \mathrm{~A} / \%$ & Assignment \\
\hline Sing & -0.21 & - & 0.32 & & 2.9 & 3.4 & Fe-nanoparticles \\
\hline D1 & 0.44 & 0.71 & 0.7 & & 35.1 & 42.7 & $\mathrm{Fe}^{2+} \mathrm{N}_{4} / \mathrm{C}, \mathrm{LS}^{26,45}$ \\
\hline D2 & 0.53 & 2.60 & 1.2 & & 41.0 & 16.1 & $\begin{array}{l}\mathrm{Fe}^{2+} \mathrm{N}_{4}, \mathrm{MS} \text {, similar } \\
\text { to } \mathrm{FePc}^{47,51}\end{array}$ \\
\hline D3 & 0.35 & 1.57 & 0.75 & & 21.0 & 28.4 & $\mathrm{Fe}^{2+} \mathrm{N}_{4} / \mathrm{C}, \mathrm{MS}^{48}$ \\
\hline Sext a & 0.15 & 0 & 0.6 & 20.0 & - & 4.3 & $\mathrm{Fe}_{3} \mathrm{C}$ \\
\hline Sext b & 0.21 & 0 & 0.6 & 17 & - & 5.1 & \\
\hline
\end{tabular}

${ }^{a} \delta_{\text {iso }}$ : isomeric shift; $\Delta E_{\mathrm{Q}}$ : quadrupole splitting; fwhm: full width at half maximum; $H_{\mathrm{o}}$ : intensity of the internal magnetic field; LS: low spin; MS: mediate spin. 

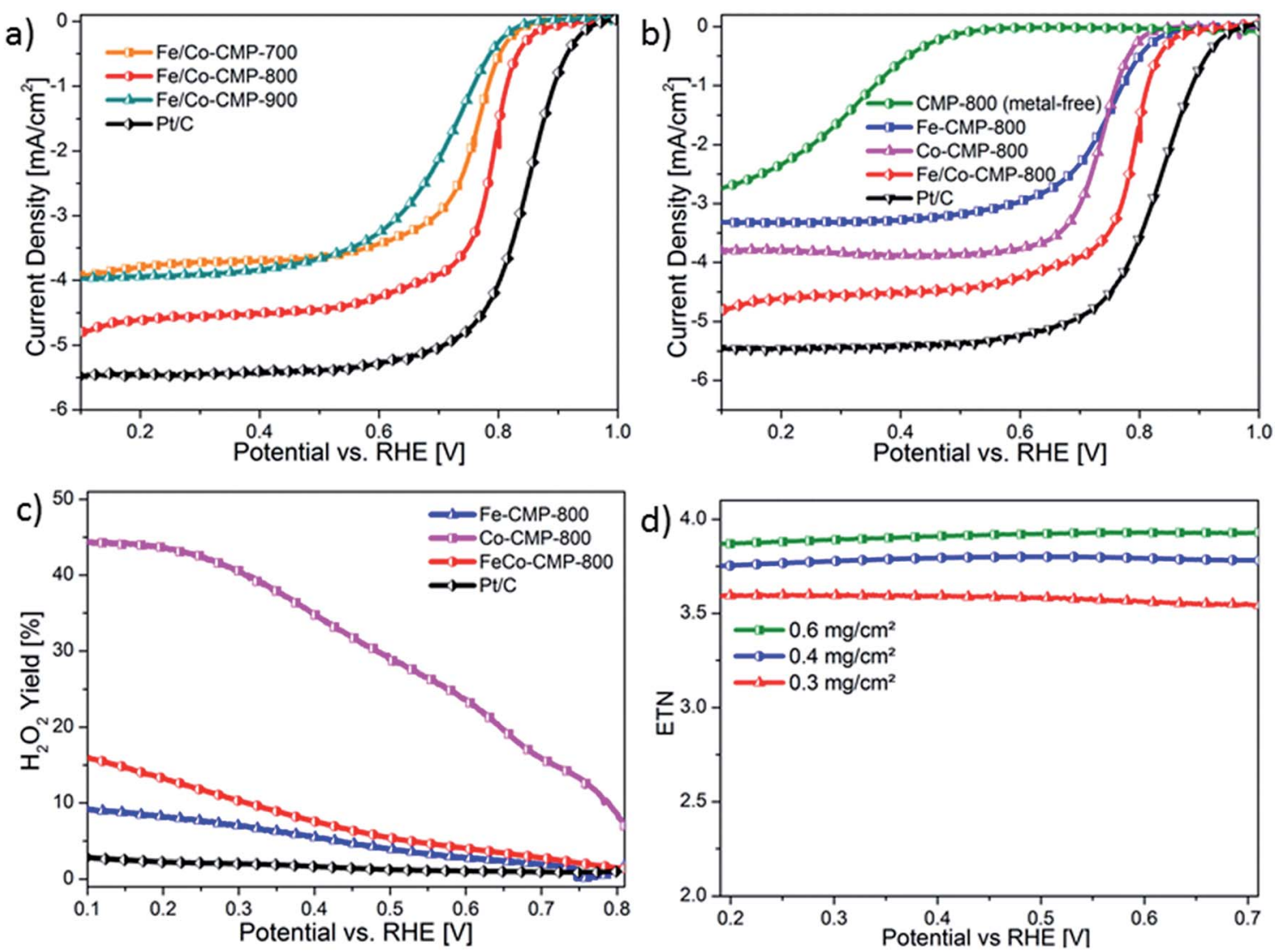

Fig. 5 Electrocatalytic performance of the catalysts. (a) ORR polarization plots of Fe/Co-CMP-700, Fe/Co-CMP-800, Fe/Co-CMP-900 and Pt/ C. (b) ORR polarization plots of Fe-CMP-800, Co-CMP-800, Fe/Co-CMP-800, metal-free CMP-800 and Pt/C. (c) $\mathrm{H}_{2} \mathrm{O}_{2}$ yield of Fe-CMP-800, Co-CMP-800, Fe/Co-CMP-800 with loadings of $0.6 \mathrm{mg} \mathrm{cm}^{-2}$ and Pt/C. (d) ETN of Fe/Co-CMP-800 in correlation with catalyst loading. RDE and RRDE measurements were conducted in $\mathrm{O}_{2}$-saturated $0.5 \mathrm{M} \mathrm{H}_{2} \mathrm{SO}_{4}$ (non-Pt catalysts) and $0.1 \mathrm{M} \mathrm{HClO}_{4}(\mathrm{Pt} / \mathrm{C}$ ) at $1600 \mathrm{rpm}$ with a sweep rate of $5 \mathrm{mV} \mathrm{s}^{-1}$.

$\mathrm{H}_{2} \mathrm{O}_{2}$ formation for all three catalysts increased with decreasing potential. For Co-CMP-800, it exceeded $40 \%$ at $U<0.25 \mathrm{~V}$, demonstrating less selectivity for cobalt-based electrocatalysts. ${ }^{57}$ For the iron-containing catalysts Fe-CMP-800 and Fe/Co-CMP-800, a 4e $\mathrm{e}^{-}$-transfer was almost exclusively observed. In particular, in the potential range of $0.6 \mathrm{~V}$ to $0.8 \mathrm{~V}-$ that is the intended range for fuel cell applications - iron-based FeCMP-800 exhibits a high selectivity, generating only $2.8 \%$ to $1.3 \% \mathrm{H}_{2} \mathrm{O}_{2}$, respectively. In terms of selectivity, the bimetallic catalyst Fe/Co-CMP-800 behaves more similarly to iron-containing Fe-CMP-800 than to Co-CMP-800. We assume that for Fe/Co-CMP-800, both active sites of $\mathrm{FeN}_{4}$ and $\mathrm{CoN}_{4}$ contribute to the ORR. At the $\mathrm{FeN}_{4}$-sites, oxygen is primarily reduced by a $4 \mathrm{e}^{-}$pathway, whereas $\mathrm{CoN}_{4}$-sites tend to reduce oxygen by a $2 \mathrm{e}^{-}$pathway. In the bimetallic catalyst, $\mathrm{H}_{2} \mathrm{O}_{2}$ produced at the $\mathrm{CoN}_{4}$-sites can be readily reduced to water at neighboring $\mathrm{FeN}_{4}$ sites resulting in a fast $2 \times 2 \mathrm{e}^{-}$pathway as indicated by the catalyst loading correlation (Fig. $5 d$ ).$^{58}$ Since Fe/Co-CMP-800 is obtained from a precursor based on Suzuki polymerization, both active sites are located in close proximity, thus realizing the $2 \times 2 \mathrm{e}^{-}$pathway with high efficiency. In the case of carbonized catalysts, this pathway is more likely than the proposed mechanism of nanostructured catalysts with geometrically confined active sites consisting of two $\mathrm{MN}_{4}$ units with face-to-face arrangement of the metal centers. ${ }^{59}$ Additionally, Fe/Co-CMP-800 demonstrates a limiting current density of $4.5 \mathrm{~mA} \mathrm{~cm}{ }^{-2}$, while Fe-CMP-800 merely reaches $3.3 \mathrm{~mA} \mathrm{~cm}^{-2}$. Considering the similar specific surface areas and the equal $\mathrm{H}_{2} \mathrm{O}_{2}$ evolution of Fe/Co-CMP800 and Fe-CMP-800, the bimetallic catalyst contains more catalytic active sites, which is in agreement with the results from the Mössbauer analysis.

Furthermore, the long-term stability of Fe/Co-CMP-800 was demonstrated by performing continuous reduction/oxidation cycles $(0.6 \mathrm{~V}-1.0 \mathrm{~V})$ at $50 \mathrm{mV} \mathrm{s}{ }^{-1}$ in an oxygen-saturated electrolyte before each LSV. Our bimetallic catalyst exhibits similar stability to the commercial Pt/C catalyst, whereas other nonnoble metal catalysts cannot compete with $\mathrm{Pt} / \mathrm{C}$ in terms of long-term stability (Fig. S9†).4,60

\section{Conclusions}

In conclusion, we have demonstrated a template-free synthesis of $\mathrm{Fe} / \mathrm{Co}$ nitrogen-doped carbon catalysts derived from the bimetallic porphyrin based conjugated polymer networks with intrinsic porosity, large surface areas, excellent thermal stability and high densities of precisely connected $\mathrm{MN}_{4}$ units. 
The bimetallic catalyst combines the physical properties of the cobalt-based catalyst (discontinuous, ribbon-like structure) with the advantages of the electrochemical properties of ironbased catalysts (high onset potential, low hydrogen peroxide evolution). Therefore, the bimetallic catalyst benefits from the following aspects resulting in an improvement of the electrochemical performance towards the ORR: (1) due to the presence of $\mathrm{CoN}_{4}$, the formation of catalytically inactive nanoparticles is diminished and the ratio of the catalytically active $\mathrm{FeN}_{4}$-species is increased; (2) the poor catalytic selectivity of $\mathrm{CoN}_{4}$ is compensated by the spatial proximity of $\mathrm{CoN}_{4}$ - and $\mathrm{FeN}_{4}$-sites; and (3) a higher electron density beneficial for the ORR at the $\mathrm{FeN}_{4}$-sites is achieved. With this enhanced comprehension, we believe that the performance of nonprecious metal-based ORR catalysts could be further improved via the rational positioning of active $\mathrm{MN}_{4}$ sites in the carbon matrix, which would help develop novel electrocatalysts for various electrochemical reactions.

\section{Acknowledgements}

This work was financially supported by the Max Planck Society through the program MaxNet Energy, ERC grant on NANOGRAPH, the project INSOLCELL and EC Graphene Flagship (CNECT-ICT-604391). Financial support by the DFG funding of the Excellence Initiative, Darmstadt Graduate School of Excellence Energy Science and Engineering (GSC 1070) is gratefully acknowledged by UIK. We would like to thank Katrin Kirchhoff, Gunnar Glasser and Dr Ingo Lieberwirth for their expert help in taking HRTEM images and Robert Graf for solid-state NMR experiments.

\section{References}

1 H. A. Gasteiger, S. S. Kocha, B. Sompalli and F. T. Wagner, Appl. Catal., B, 2005, 56, 9-35.

2 I. E. L. Stephens, A. S. Bondarenko, U. Gronbjerg, J. Rossmeisl and I. Chorkendorff, Energy Environ. Sci., 2012, 5, 6744-6762.

3 Z. Yang, Z. Yao, G. Li, G. Fang, H. Nie, Z. Liu, X. Zhou, X. A. Chen and S. Huang, ACS Nano, 2011, 6, 205-211.

4 H. R. Byon, J. Suntivich and Y. Shao-Horn, Chem. Mater., 2011, 23, 3421-3428.

5 F. Y. Cheng, J. A. Shen, B. Peng, Y. D. Pan, Z. L. Tao and J. Chen, Nat. Chem., 2011, 3, 79-84.

6 D. K. Dogutan, S. A. Stoian, R. McGuire Jr., M. Schwalbe, T. S. Teets and D. G. Nocera, J. Am. Chem. Soc., 2011, 133, 131-140.

7 P. He, M. Lefevre, G. Faubert and J. P. Dodelet, J. New Mater. Electrochem. Syst., 1999, 2, 243-251.

8 T. Sawaguchi, T. Itabashi, T. Matsue and I. Uchida, J. Electroanal. Chem., 1990, 279, 219-230.

9 O. Solorzaferia, K. Ellmer, M. Giersig and N. Alonsovante, Electrochim. Acta, 1994, 39, 1647-1653.

$10 \mathrm{H}$. Behret, H. Binder and G. Sandstede, Electrochim. Acta, 1975, 20, 111-117.
11 H. Wang, Y. Liang, Y. Li and H. Dai, Angew. Chem., Int. Ed., 2011, 50, 10969-10972.

12 A. Ishihara, Y. Ohgi, K. Matsuzawa, S. Mitsushima and K. Ota, Electrochim. Acta, 2010, 55, 8005-8012.

13 F. Y. Cheng, J. Shen, W. Q. Ji, Z. L. Tao and J. Chen, ACS Appl. Mater. Interfaces, 2009, 1, 460-466.

14 R. Jasinski, Nature, 1964, 201, 1212-1213.

15 K. Wiesener, Electrochim. Acta, 1986, 31, 1073-1078.

16 T. Schilling and M. Bron, Electrochim. Acta, 2008, 53, 53795385.

17 L. Birry, J. H. Zagal and J. P. Dodelet, Electrochem. Commun., 2010, 12, 628-631.

18 M. Ferrandon, A. J. Kropf, D. J. Myers, K. Artyushkova, U. Kramm, P. Bogdanoff, G. Wu, C. M. Johnston and P. Zelenay, J. Phys. Chem. C, 2012, 116, 16001-16013.

19 B. Mondal, K. Sengupta, A. Rana, A. Mahammed, M. Botoshansky, S. G. Dey, Z. Gross and A. Dey, Inorg. Chem., 2013, 52, 3381-3387.

20 N. Larouche, R. Chenitz, M. Lefevre, E. Proietti and J. P. Dodelet, Electrochim. Acta, 2014, 115, 170-182.

21 H. W. Liang, W. Wei, Z. S. Wu, X. L. Feng and K. Mullen, J. Am. Chem. Soc., 2013, 135, 16002-16005.

22 D. M. Drazic, Z. V. Ledinski and S. K. Zecevic, J. Appl. Electrochem., 1983, 13, 337-340.

23 S. Gupta, D. Tryk, I. Bae, W. Aldred and E. Yeager, J. Appl. Electrochem., 1989, 19, 19-27.

24 S. L. Gojkovic, S. Gupta and R. F. Savinell, J. Electrochem. Soc., 1998, 145, 3493-3499.

25 K. Lee, L. Zhang, H. Lui, R. Hui, Z. Shi and J. J. Zhang, Electrochim. Acta, 2009, 54, 4704-4711.

26 U. I. Kramm, J. Herranz, N. Larouche, T. M. Arruda, M. Lefevre, F. Jaouen, P. Bogdanoff, S. Fiechter, I. AbsWurmbach, S. Mukerjee and J. P. Dodelet, Phys. Chem. Chem. Phys., 2012, 14, 11673-11688.

27 U. I. Kramm, I. Herrmann-Geppert, P. Bogdanoff and S. Fiechter, J. Phys. Chem. C, 2011, 115, 23417-23427.

28 U. I. Koslowski, I. Abs-Wurmbach, S. Fiechter and P. Bogdanoff, J. Phys. Chem. C, 2008, 112, 15356-15366.

29 C. Klinke and K. Kern, Nanotechnology, 2007, 18, 215601.

30 C. Klinke, J. M. Bonard and K. Kern, J. Phys. Chem. B, 2004, 108, 11357-11360.

31 U. I. Kramm, I. Herrmann, S. Fiechter, G. Zehl, I. Zizak, I. Abs-Wurmbach, J. Radnik, I. Dorbandt and P. Bogdanoff, ECS Trans., 2009, 25, 659-670.

32 I. Herrmann, U. I. Kramm, J. Radnik, S. Fiechter and P. Bogdanoff, J. Electrochem. Soc., 2009, 156, B1283-B1292.

33 M. Bron, S. Fiechter, M. Hilgendorff and P. Bogdanoff, J. Appl. Electrochem., 2002, 32, 211-216.

34 U. I. Kramm, I. Herrmann-Geppert, S. Fiechter, G. Zehl, I. Zizak, I. Dorbandt, D. Schmeisser and P. Bogdanoff, $J$. Mater. Chem. A, 2014, 2, 2663-2670.

35 R. L. Liu, D. Q. Wu, X. L. Feng and K. Mullen, Angew. Chem., Int. Ed., 2010, 49, 2565-2569.

36 Z. S. Wu, S. B. Yang, Y. Sun, K. Parvez, X. L. Feng and K. Mullen, J. Am. Chem. Soc., 2012, 134, 9082-9085.

37 E. Proietti, F. Jaouen, M. Lefevre, N. Larouche, J. Tian, J. Herranz and J. P. Dodelet, Nat. Commun., 2011, 2, 416. 
38 S. Yuan, J. L. Shui, L. Grabstanowicz, C. Chen, S. Commet, B. Reprogle, T. Xu, L. Yu and D. J. Liu, Angew. Chem., Int. Ed., 2013, 52, 8349-8353.

39 Z. S. Wu, L. Chen, J. Liu, K. Parvez, H. Liang, J. Shu, H. Sachdev, R. Graf, X. Feng and K. Mullen, Adv. Mater., 2014, 26, 1450-1455.

40 A. Serov, M. H. Robson, M. Smolnik and P. Atanassov, Electrochim. Acta, 2012, 80, 213-218.

41 Q. Lin, X. Bu, A. Kong, C. Mao, F. Bu and P. Feng, Adv. Mater., 2015, 27, 3431-3436.

42 G. Wu, K. L. More, C. M. Johnston and P. Zelenay, Science, 2011, 332, 443-447.

43 A. D. Adler, F. R. Longo, J. D. Finarelli, J. Goldmacher, J. Assour and L. Korsakoff, J. Org. Chem., 1967, 32, 476.

44 L. Chen, Y. Yang and D. Jiang, J. Am. Chem. Soc., 2010, 132, 9138-9143.

45 H. W. Spiess, in NMR Spectroscopy of Polymers: Innovative Strategies for Complex Macromolecules, American Chemical Society, 2011, vol. 1077, ch. 2, pp. 17-35.

46 K. E. Hart, J. M. Springmeier, N. B. McKeown and C. M. Colina, Phys. Chem. Chem. Phys., 2013, 15, 2016120169.

47 S. L. Gojkovic, S. Gupta and R. F. Savinell, Electrochim. Acta, 1999, 45, 889-897.

48 U. I. Kramm, M. Lefevre, N. Larouche, D. Schmeisser and J. P. Dodelet, J. Am. Chem. Soc., 2014, 136, 978-985.

49 J. Wang, K. Li, H.-X. Zhong, D. Xu, Z.-L. Wang, Z. Jiang, Z.-J. Wu and X.-B. Zhang, Angew. Chem., 2015, 127, 1067610680.
50 J. Herranz, F. Jaouen, M. Lefevre, U. I. Kramm, E. Proietti, J. P. Dodelet, P. Bogdanoff, S. Fiechter, I. Abs-Wurmbach, P. Bertrand, T. M. Arruda and S. Mukerjee, J. Phys. Chem. C, 2011, 115, 16087-16097.

51 R. Taube, H. Drevs, E. Fluck, P. Kuhn and K. F. Brauch, Z. Anorg. Allg. Chem., 1969, 364, 297-315.

52 J. T. Sage, Y. M. Xia, P. G. Debrunner, D. T. Keough, J. de Jersey and B. Zerner, J. Am. Chem. Soc., 1989, 111, 7239-7247.

53 C. P. Deck and K. Vecchio, Carbon, 2006, 44, 267-275.

54 L. Dignardbailey, M. L. Trudeau, A. Joly, R. Schulz, G. Lalande, D. Guay and J. P. Dodelet, J. Mater. Res., 1994, 9, 3203-3209.

55 U. I. Kramm, I. Abs-Wurmbach, I. Herrmann-Geppert, J. Radnik, S. Fiechter and P. Bogdanoff, J. Electrochem. Soc., 2011, 158, B69-B78.

56 Z. Xiang, Y. Xue, D. Cao, L. Huang, J. F. Chen and L. Dai, Angew. Chem., Int. Ed., 2014, 53, 2433-2437.

57 S. Marcotte, D. Villers, N. Guillet, L. Roué and J. P. Dodelet, Electrochim. Acta, 2004, 50, 179-188.

58 A. Bonakdarpour, M. Lefevre, R. Z. Yang, F. Jaouen, T. Dahn, J. P. Dodelet and J. R. Dahn, Electrochem. Solid-State Lett., 2008, 11, B105-B108.

59 J. Y. Cheon, T. Kim, Y. Choi, H. Y. Jeong, M. G. Kim, Y. J. Sa, J. Kim, Z. Lee, T. H. Yang, K. Kwon, O. Terasaki, G. G. Park, R. R. Adzic and S. H. Joo, Sci. Rep., 2013, 3, 2715.

60 F. Hasche, M. Oezaslan and P. Strasser, Phys. Chem. Chem. Phys., 2010, 12, 15251-15258. 